\title{
Granular cell tumor of rectum: Report of a case and review of literature
}

\author{
Fariba Binesh ${ }^{1}$, Nazanin Soleimani ${ }^{2}$, Fatemeh Pourhosseini ${ }^{1}$, Seyed Hossein Shahcheraghi*3,4, \\ 1 Department of Pathology, Shahid Sadoughi University of Medical Sciences, Yazd, Iran \\ 2 Medical student, Shahid Sadoughi University of Medical Sciences, Yazd, Iran \\ 3 Department of Modern Sciences \& Technologies, School of Medicine, Mashhad University of Medical Sciences, Mashhad, Iran \\ 4 Infectious Diseases Research Center, Shahid Sadoughi Hospital, Shahid Sadoughi University of Medical Sciences, Yazd, Iran \\ *Corresponding Author: Dr. Seyed Hossein Shahcheraghi, Department of Modern Sciences \& Technologies, School of Medicine, \\ Mashhad University of Medical Sciences, Mashhad, Iran Email: shahcheraghih@gmail.com, Tel: 00989132531389
}

Received: February 24, 2019; Accepted: June 02, 2019

\section{Abstract}

Granular cell tumor (GCT) is a benign soft tissue neoplasm. This tumor can be seen in any part of the body; however, its occurrence is unusual in the rectum. Here, we report a case of granular cell tumor of the rectum.

Keywords: Granular cell tumor, Neoplasm, Rectum.

\section{INTRODUCTION}

GCT is a benign soft tissue neoplasm. The main characteristic feature of which is large cells with a granular cytoplasm [1]. It was initially believed that it originated from myoblast but nowadays scientists believe it originates from Schwann cells [2]. This tumor can be seen in any part of the body [1], but it is most commonly seen in skin, subcutaneous tissue, tongue, oral cavity and breast [3]. It is rarely seen in the gastrointestinal tract where it is often represented as a small asymptomatic polyp [4]. The most common site of it in the gastrointestinal tract is esophagus, followed by duodenum, anus, and stomach, and its occurrence is unusual in the rectum $[5,6]$.

Here, is a case of a granular cell tumor of the rectum. We have also reviewed the literature in this regard.

\section{CASE REPORT}

The patient was a 58-year-old man who referred to Shahid Sadoughi outpatient clinic with the chief complaint of bloody diarrhea. Endoscopic examination revealed an internal hemorrhoid and an $8 \mathrm{~mm}$ sessile polyp which was removed by endoscopy. The other parts of the large intestine to the terminal ileum did not show any specific pathologic changes. The resected specimen was sent to the pathology department. Grossly, the specimen consisted of a $7^{\star} 6^{\star} 5 \mathrm{~mm}$, creamy soft polyp. Microscopically the polyp was composed of large cells with regular round nucleus and granular cytoplasm that was covered on the surface by large intestinal mucosa. These cells were arranged as cellular nests (fig1).

Immunohistochemically the tumor cells were strongly $\mathbf{S 1 0 0}$ positive (fig-2).

\section{DISCUSSION}

GCT was first described by Abrikossoff in 1926, and since then many cases of this type of tumor have been reported [1]. Most of these lesions represent as asymptomatic nodules or papules, with a diameter of less than $3 \mathrm{~cm}$, which are not well defined and usually involve subcutaneous or sub mucosal tissues. GCTs are generally solitary, but multiple GCTs are also reported [7]. Initially, regarding the microscopic appearance of these lesions, they were thought to have a myoblastic origin [2]. But nowadays, the presence of S100 protein and vimentin in tumor cells, reveal Schwann cells as a precursor of them. GCT can occur anywhere, although it is most commonly found in the head and neck region. Some studies show more prevalence in women and in the fourth to sixth decades of life [7]. The most common site of it in the gastrointestinal tract is esophagus, followed by duodenum, anus, and stomach, and its occurrence is unusual in the rectum $[5,6]$ It is often found accidentally in a colorectal endoscopy for other reasons [5]. Clinically, these lesions are similar to other benign and malignant neoplasms, such as fibromas, lymphomas and neurofibromas [7].

It is rarely possible to diagnose GCT based on endoscopic appearance, and its final diagnosis is based on pathologic 
findings [6]. Histopathologically, GCTs are composed of large cells with small nuclei and ample eosinophilc cytoplasm containing a large number of PAS-positive acidophilic granules $[6,7]$. They are typically benign but can recur. Nevertheless, about $2 \%$ of them have malignant behavior [1]. The malignancy in GCT is related to their size, so more than $60 \%$ of the metastatic GCTs have a diameter of more than $4 \mathrm{~cm}$ [6]. Treatment of GCT is complete removal of the tumor and if the tumor is not completely removed, the relapse rate will be between $15 \%$ and $50 \%$ [8].
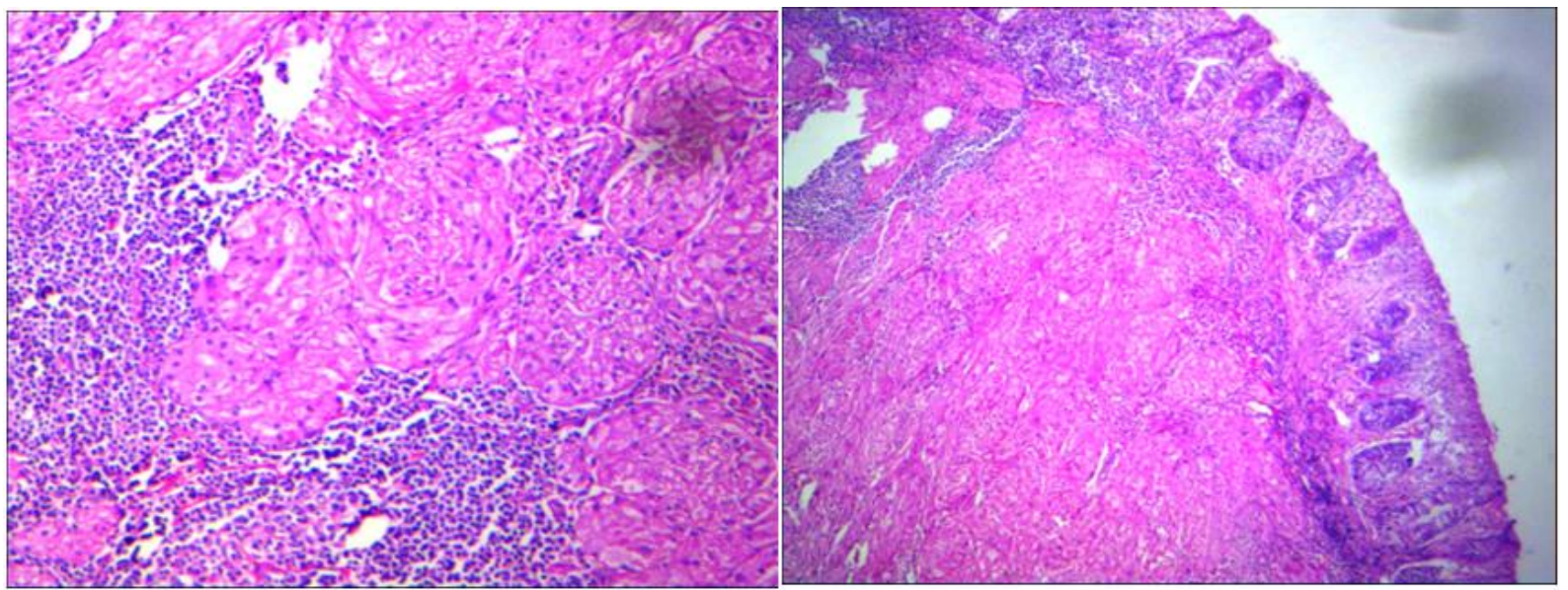

Fig 1: Section shows that the polyp was composed of large cells with regular round nucleus and granular cytoplasm and they are covered on the surface by large intestinal mucosa(X10 \&40).

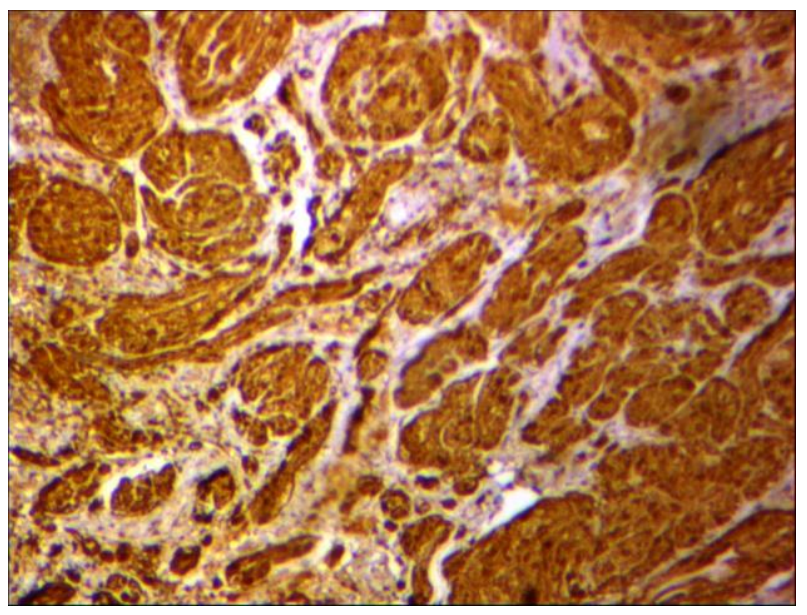

Fig 2: Immunohistochemically the tumor cells are strongly S100 positive

None declared

\section{CONCLUSION}

GCT of the rectum is rare. It is important to discriminate this tumor from other endoscopically similar tumors of the rectum.

\section{Acknowledgement}

None.

\section{Conflict of Interest}

\section{Financial Support}

None declared

\section{REFERENCES}

1. Stemm M, Suster D, Wakely Jr PE, Suster S. Typical and Atypical Granular Cell Tumors of Soft Tissue: A Clinicopathologic Study of 50 Patients. Am j clinical pathology. 2017;148(2):161-6. 
2. Esterson YB, Edelman MC, Lipskar AM, Glassman LR, Assaad P. A case of bronchial granular cell tumor in a pediatric patient. Clinical imaging. 2017;43:15-8.

3. Nakanome T, Yokoyama K, Takeuchi H, Haruki S, Sada M, Kobayashi K, et al. Rectal Granular-Cell Tumor Difficult To Distinguish From Carcinoid Tumor. Digestive Endoscopy. 2010;22(4):325-8.

4. Berzal CM, González MA, Torío SB. Granular cell tumor of cecum. Revista espanola de enfermedades digestivas: organo oficial de la Sociedad Espanola de Patologia Digestiva. 2016;108(6):364.

5. Nakachi A, Miyazato H, Oshiro T, Shimoji H, Shiraishi M, Muto Y. Granular cell tumor of the rectum: a case report and review of the literature. Journal of gastroenterology. 2000;35(8):631-4.

6. Sohn D-K, et al. Granular cell tumor of colon: report of a case and review of literature. World Journal of Gastroenterology: WJG. 2004;10(16):2452.

7. Ferreira JCB, Oton-Leite AF, Guidi R, Mendonça EF. Granular cell tumor mimicking a squamous cell carcinoma of the tongue: a case report. BMC research notes. 2017;10(1):14.

8. Al-Dawsari NA, Amra N. Granular cell tumor on the chest of a 9year-old female: case report and a retrospective analysis. Journal of cutaneous medicine and surgery2015;19(3):328-30. 